\title{
AS DEFICIÊNCIAS DE MEDIDAS MITIGADORAS DE UM RCA QUE COMPROMETE O PRINCÍPIO DO DESENVOLVIMENTO SUSTENTÁVEL
}

\author{
Robson Garcia da Silva \\ robsontecnologo@yahoo.com.br
}

\section{RESUMO}

Este trabalho tem como propósito fundamental analisar as deficiências de medidas mitigadoras de impactos que compromete o princípio do desenvolvimento sustentável, propostas pelo Relatório de Controle Ambiental (RCA) para a perfuração de seis poços de petróleo no campo petrolífero de Porto Carão, município de Carnaubais (RN). Esse estudo ambiental visa à concessão da Licença Prévia para a Perfuração (LPper) desses poços. Para consecução deste trabalho utilizou-se os estudos realizados pelo Ministério Público Federal (MPF, 2004) que são a respeito das principais deficiências no item de mitigação e compensação de impactos em estudos de impacto ambiental no Brasil. Além disso, utilizou-se os aportes teóricos de alguns autores a cerca do licenciamento ambiental e princípio do desenvolvimento sustentável além de técnicas de pesquisa exploratória, realizadas por meio de levantamentos bibliográficos, documentais e legais, como as leis federais e estaduais e as resoluções atinentes ao tema. Para análise em tela, foi selecionado o RCA da empresa Petróleo Brasileiro S.A. (PETROBRAS), elaborado pela Empresa de Consultoria e Planejamento Ambiental Ltda. (ECOPLAM), que fora solicitado para emissão dessa licença. Como resultados e discussão deste estudo, constataram-se que $46 \%$, ou o equivalente a 13 (treze) medidas de um universo de 28 (vinte e oito), apresentaram deficiências que podem vir a comprometer a qualidade desse estudo ambiental e principalmente o princípio do desenvolvimento sustentável.

PALAVRAS-CHAVE: medidas mitigadoras, Relatório de Controle Ambiental (RCA), princípio do desenvolvimento sustentável.

\section{THE DEFICIENCIES OF MEASURES MITIGATING OF A RCA THAT IT COMPROMISSES THE PRINCIPLE OF THE SUSTAINABLE DEVELOPMENT}

\begin{abstract}
This work has the fundamental meant analyze the deficiences of measures of mitigating environmental impacts that it compromises the principle of the sustainable development, proposals by the Environmental Control Report (RCA) for drilling six oil wells in the Porto Carão, municipality of Carnaubais (RN). This environmental study aims to grant a prior permit for drilling (LPer) of these wells. To achieve this used the studies carried through for Federal Public Ministry (MPF, 2004) that they are regarding the main deficiencies in the item of mitigation and compensation of impacts in studies of environmental impact in Brazil. Moreover, this used intake theoretical of some others on environmental licensing and principle of sustainable development and exploratory research techniques, made through withdrawals bibliographic, documentary and legal, as the federal and state laws, resolutions relating to the subject. To analysis on screen, was chosen the RCA of Petróleo Brasileiro S.A. (PETROBRAS), by Empresa de Consultoria e Planejamento Ambiental Ltda. (ECOPLAM), which had been requested to issue such licence. As results and discussion of this study, we find that $46 \%$, or the equivalent the 13 (thirteen) measured of a universe of 28 (twenty and
\end{abstract}


eight), they had presented deficiencies that can come to compromise the quality of this environmental study and mainly the principle of sustainable development.

KEY-WORDS: measures mitigating, Environmental Control Report (RCA), principle of sustainable development. 


\section{AS DEFICIÊNCIAS DE MEDIDAS MITIGADORAS DE UM RCA QUE COMPROMETE O PRINCÍPIO DO DESENVOLVIMENTO SUSTENTÁVEL}

\section{INTRODUÇÃO}

Ao longo dos últimos anos, a exploração e produção de petróleo onshore, ou seja, em terra, vêm se constituindo num dos vetores mais importantes para a economia do Estado do Rio Grande do Norte. A perfuração de poços petrolíferos onshore vem aumentando de maneira significativa o número de solicitações e emissões de licenças ambientais junto ao Instituto de Desenvolvimento Sustentável e Meio Ambiente (IDEMA) do Rio Grande do Norte, órgão ambiental competente pelo licenciamento ambiental do Estado. Por conseguinte, isso tem elevado também o número de elaboração de estudos ambientais para subsidiar o licenciamento dessas atividades.

No ano de 2008, por exemplo, o IDEMA emitiu um total de 5326 licenças ambientais sendo que $76 \%$ desse percentual, o que a equivale a 4047, são referentes às atividades petrolíferas onshore (SILVA, 2009).

Para uma melhor visualização e entendimento desses dados, o gráfico 1, demonstra a quantidade aproximada de licenças ambientais emitidas em cada mês do ano de 2008 tanto do âmbito das outras atividades quanto no âmbito das licenças ambientais da atividade onshore.

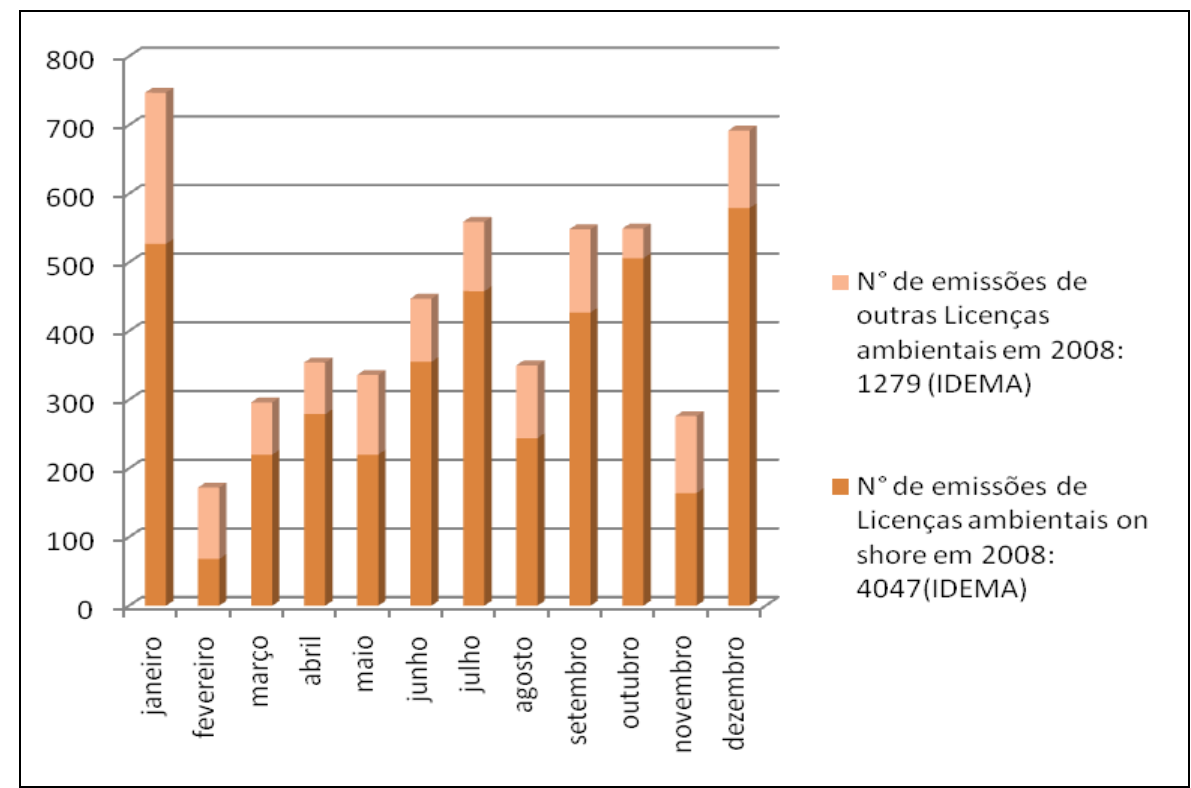

\section{Gráfico 1 - Quantidade de licenças ambientais emitidas nos meses de 2008 Fonte: Silva (2009)}

Com base no Gráfico 1, notamos que na maioria desses meses há uma significativa predominância das emissões de licenças ambientais de atividades petrolíferas onshore o que nos leva a reiterar o elevado número de estudos ambientais para subsidiar o licenciamento dessas atividades.

Além de gerar riquezas, o desenvolvimento dessas atividades oferece elevados riscos de impactos ambientais ao meio ambiente.

Nesse contexto, o licenciamento ambiental como um instrumento disposto na Lei 6938/81, Política Nacional do Meio Ambiente, nas resoluções do Conselho Nacional do Meio Ambiente (CONAMA) e nas normas estaduais, Lei Complementar 272/04 e Lei 
Complementar 336/06 do RN, pode vir a oferecer medidas de controle ambiental que possibilitem a prevenção, diminuição e/ou compensação de impactos ambientais negativos de qualquer atividade humana visando o desenvolvimento sustentável.

Esse instrumento é conduzido no âmbito do poder público, e é considerado um procedimento administrativo e de gestão do ambiente, uma vez que por meio deste a administração pública busca exercer o controle sobre as atividades humanas que interferem nas condições ambientais, o que isso pode levar a uma compatibilização do desenvolvimento econômico atrelado a preservação do meio ambiente (MILARÉ, 2005).

No processo de licenciamento ambiental da atividade petrolífera onshore do RN, os estudos ambientais elaborados por empresas cadastradas pelo IDEMA, apesar de atenderem os termos de referência, não apresentam conteúdos consistentes e aprofundados, o que dificulta numa análise profícua no entendimento de impactos ambientais e da proposição de medidas mitigadoras desses impactos (PEGADO; SILVA, 2008).

Em consonância com isso, colocamos em destaque o problema da qualidade de estudos ambientais voltados para a exploração e produção de petróleo onshore do RN, visto que, em muitas vezes não vêm atendendo plenamente os ditames da legislação e, conseqüentemente, comprometendo os princípios do direito ambiental como o da precaução, prevenção, da supremacia do bem ambiental, do poluidor-pagador, da função social e ambiental, da propriedade, da cooperação internacional, do desenvolvimento sustentável etc.

Dentre esses, o princípio do desenvolvimento sustentável ocupa posição de preponderância, haja vista numa escala axiológica, influenciar, complementar e orientar os demais, viabilizando o trato correto, seguro e adequado à temática ambiental (VIANNA, 2009).

Em face disso, o presente trabalho procurou responder o seguinte questionamento: em que grau as medidas mitigadoras de impactos ambientais propostas pelo Relatório de Controle Ambiental (RCA), vêm apresentando deficiências que comprometem na qualidade desse estudo ambiental e, por conseguinte, com o princípio do desenvolvimento sustentável, visando à concessão da Licença Prévia para Perfuração (LPper)?

Nesse sentido, este trabalho tem como propósito fundamental analisar as deficiências das medidas mitigadoras dos impactos ambientais propostas pelo Relatório de Controle Ambiental (RCA) para a perfuração de seis poços de petróleo no campo petrolífero de Porto Carão, localizado na zona rural do município de Carnaubais (RN) que compromete o princípio do desenvolvimento sustentável.

Entendemos, neste estudo, como medidas mitigadoras de impactos ambientais ações propostas que têm como intuito reduzir a magnitude ou importância dos impactos ambientais negativos (SÁNCHEZ, 2006).

Sobre o princípio do desenvolvimento sustentável, entendemos que, em linhas gerais, é aquele que busca compatibilizar o desenvolvimento de atividades econômicas em equilíbrio a proteção do meio ambiente (MILARÉ, 2000).

$\mathrm{O}$ vocábulo princípio que origina-se do latim principium, pincipii, significa "aquilo que se toma por primeiro". O que se sugere, pois, início, começo, fonte, alicerce, base, ponto de partida. No âmbito jurídico, sem se descurar totalmente de seu sentido etimológico, os princípios consistem em enunciados fundamentais que condicionam e dão estrutura ao sistema, porquanto the conferem unidade e coerência (VIANNA, 2009). 
Ademais, destacamos também os estudos que nortearam a análise em pauta, realizados pelo Ministério Público Federal (MPF, 2004) sobre a análise de deficiências de estudos de impactos ambientais no Brasil.

Este trabalho surgiu a partir de uma monografia resultado da pesquisa de iniciação científica financiada pelo Programa de Mobilização da Indústria de Petróleo e Gás Natural (PROMINP) no período de julho de 2008 a março de 2009 no Núcleo de Pesquisa em Processos de Petróleo e Gás Natural (NPP3G) do Instituto Federal de Educação, Ciência e Tecnologia do Rio Grande do Norte (IFRN).

A justificativa deste trabalho decorreu de inúmeros problemas que estudos ambientais utilizados no processo de licenciamento onshore, têm apresentado junto ao órgão ambiental do Estado, o IDEMA. Exemplo disso é o caso do RCA em análise.

\section{FUNDAMENTAÇÃO TEÓRICA}

O capítulo em tela apresenta a discussão teórica sobre os conceitos norteadores deste trabalho que são: o de princípio de desenvolvimento sustentável, enquanto um princípio jurídico implícito no art. 225 e 170 da Constituição Federal do Brasil, o de licenciamento ambiental, o de licenciamento ambiental da atividade petrolífera onshore do RN e, finalmente, o de estudo ambiental, destacando-se nesse último, o item concernente as medidas mitigadoras do RCA, que se constitui no objeto de análise deste trabalho científico.

\section{O PRINCÍPIO DO DESENVOLVIMENTO SUSTENTÁVEL}

Neste trabalho, o princípio do desenvolvimento sustentável, tratado por Milaré (2000), possui um duplo ordenamento, ou seja, de um duplo direito. O primeiro é o direito do ser humano de se desenvolver e realizar as suas potencialidades e habilidades, tanto individualmente quanto socialmente. O segundo é o direito de assegurar às futuras gerações as mesmas condições favoráveis.

É evidente nesse princípio a associação mútua entre direito e dever, haja vista que para se desenvolver e usufruir nesse planeta devemos fazê-los de maneira racional. Mas isso não é apenas direito, é dever de toda a sociedade.

Dessa forma, quando na seguinte situação, por exemplo, estabelecemos o princípio, inserido, implicitamente, no art. 225, de que "todos têm direito ao meio ambiente ecologicamente equilibrado", "esse equilíbrio ecológico traz no bojo as condições do planeta Terra e as condições para as gerações futuras". Nesse contexto, "usufruir corretamente dos recursos ambientais: o verbo usufruir traduz um direito; o advérbio corretamente conota o dever" (MILARÉ, 2000, p.107, grifo do autor).

A introdução desse conceito em nosso país deu-se primeiramente no caso da criação de diretrizes básicas para o zoneamento industrial nas áreas críticas de poluição pela Lei 6.803, de 03 de julho de 1980.

Doravante, a legislação ambiental brasileira incorporou de maneira mais significativa esse conceito por meio da Lei 6.938/81, Política Nacional do Meio Ambiente, a qual, dentre outros instrumentos dessa lei, a Avaliação de Impactos Ambientais (AIA), seria, o principal meio de preservar os processos ecológicos essenciais. 
No $2^{\circ}$ art. dessa lei dispõe que: "A Política Nacional do Meio Ambiente tem por objetivo a preservação, melhoria e recuperação da qualidade ambiental propícia à vida, visando assegurar, no país, condições ao desenvolvimento sócio-econômico, aos interesses da segurança nacional e à proteção da dignidade da vida humana". E no art. 4: "A Política Nacional do Meio Ambiente visará: I - à compatibilização do desenvolvimento econômicosocial com a preservação da qualidade do meio ambiente e do equilíbrio ecológico "(BRASIL, 1981).

Sua formalização expressa, entretanto, decorre do Princípio $\mathrm{n}^{\circ}$ 4, insculpido na Declaração do Rio (1992), que contém a seguinte dicção: "Para se alcançar o desenvolvimento sustentável, a proteção do meio ambiente deve constituir parte integrante do processo de desenvolvimento e não pode ser considerada isoladamente em relação a ele".

Em relação à associação entre economia e desenvolvimento, Milaré (2000), afirma que o conceito de produção e consumo de bens e serviços estão inseparáveis. Além do mais, se a produção deve ser sustentável, o consumo o deve ser também. Ou seja, não produzir o que não se consome não consumir o que não se produz.

Além disso, a Constituição Federal, ao adotar o modelo econômico de produção capitalista, em seu art. 170, traz em si diretriz que não autoriza o profissional do setor produtivo a se eximir de seu compromisso social, inclusive ambiental. O texto constitucional é claro e não permite evasivas: "a ordem econômica, fundada na valorização do trabalho humano e na livre iniciativa, tem por fim assegurar a todos a existência digna, conforme os ditames da justiça social", observando-se, dentre outros princípios, "a defesa do meio ambiente" (VIANNA, 2009, grifo nosso).

Portanto, de acordo com a idéia exposta acima, é inaceitável que os empresários atuem de maneira irresponsável a respeito da valorização do trabalho humano e dos bens ambientais. Pelo contrário, devem agir de maneira ética e com responsabilidade social com os seus funcionários, com a sociedade e, inclusive, internalizar nos seus custos, os bens ambientais promovendo uma racionalização dos recursos naturais.

Ao nosso entendimento é imprescindível pensarmos em padrões de consumo sustentáveis, haja vista que, se assim não for, não erradicaremos males sociais como a miséria que, por conseguinte, atingem e comprometem sob o aspecto ambiental as condições necessárias de vida na Terra, negando o direito de assegurar às futuras gerações condições favoráveis a se desenvolver de maneira moral individualmente e socialmente. Em concordância com isso, alinha-se o Princípio n ${ }^{\circ} 8$ da Declaração do Rio (1992).

Por fim, notamos que o principio do desenvolvimento sustentável possui intrínseco o direito e dever imbricados um no outro, termos recíprocos e mutuamente condicionantes. "Daí, a legitimidade, a força e a oportunidade desse princípio como referência basilar do Direito do Ambiente" (MILARÉ, 2000, p.107).

\section{O LICENCIAMENTO AMBIENTAL}

O licenciamento ambiental para Lanna (1995, p.171), é um dos instrumentos da Política Nacional do Meio Ambiente, exigido para "a construção, instalação, ampliação e funcionamento de estabelecimento de atividades utilizadoras de recursos ambientais, consideradas efetivas ou potencialmente poluidoras".

Para a Resolução CONAMA n ${ }^{\circ}$ 237/97, o licenciamento ambiental é um procedimento administrativo pelo qual o órgão ambiental competente observa alguns aspectos como 
localização, instalação, ampliação e operação de empreendimentos e atividades utilizadoras de recursos naturais considerados efetivos ou potencialmente poluidores ou que, sob qualquer forma, possam causar degradação ambienta (BRASIL, 1997).

Prosseguindo essa discussão, Lima (2006) pontua que o licenciamento ambiental constitui um procedimento complexo que envolve análises técnicas e discussão públicadas informações produzidas, que tem como objetivo guiar o órgão licenciador na tomada de decisão quanto à implementação de atividades ou obras efetiva ou potencialmente causadora de impactos ambientais.

Por outro lado, Fink et al (2004), enfatizam que o licenciamento não se limita a um simples ato, mas, sim, a uma série de passos encadeados com vistas à verificação de que certa atividade está dentro dos padrões ambientais permitidos.

Mello (2004), por sua vez, diz que, em linhas gerais, o licenciamento ambiental, como todo procedimento administrativo, pode ser enxergado como uma sucessão itinerária e encadeada de atos administrativos que tendem, todos, a um resultado final e conclusivo.

O licenciamento ambiental é conduzido no âmbito do poder público, e é considerado um procedimento administrativo e instrumento de gestão do ambiente, uma vez que por meio deste a administração pública busca exercer o controle sobre as atividades humanas que interferem nas condições ambientais, o que isso pode levar a uma compatibilização o desenvolvimento econômico atrelada a preservação do meio ambiente (MILARÉ, 2005).

Por meio do licenciamento, o poder público avalia os possíveis impactos que a atividade pode causar, os discute com a comunidade e, através de um balanço entre custos ambientais e benefícios sociais, decide quanto à sua viabilidade ou não (LIMA, 2006).

Nesse sentido, o licenciamento ambiental exerce controle prévio das atividades que, de modo geral, tendem a causar essa degradação (FINK et al, 2004).

O licenciamento ambiental não possui um caráter de impedimento ao direito constitucional de liberdade empresarial e à propriedade privada, mas, sim, um limitador e condicionador, a fim de que se impeça que o exercício ilimitado de um direito atinja outros também muito importantes (FINK et al, 2004).

Quanto aos procedimentos do licenciamento ambiental, de maneira geral, compreende 3 (três) tipos de licença: a Licença Prévia (LP), a Licença de Instalação (LI) e a Licença de Operação (LO). Mas essas licenças podem variar de acordo com as características da atividade econômica

De uma forma simplificada, demonstraremos a seguir (ver Figura 1), o processo de licenciamento ambiental que inicia-se com o projeto da atividade realizado pelo empreendedor e conclui-se na execução da atividade. 


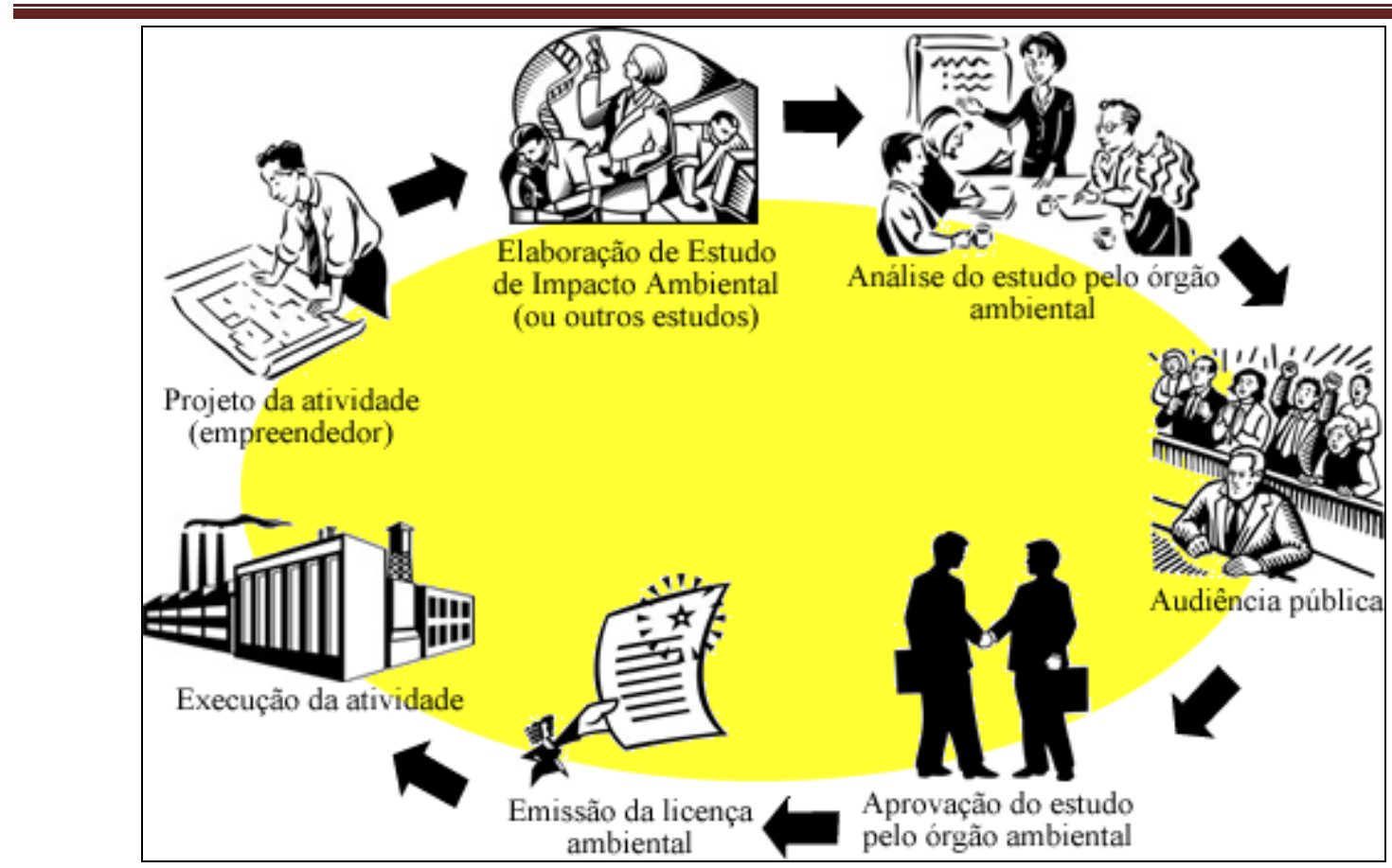

Figura 1 - Procedimentos simplificados do licenciamento ambiental Fonte: Silva (2009), adaptado de Fogliatti et al (2004)

De acordo com a Lei $\mathrm{n}^{\mathrm{o}}$. 6.938/1981 art. 10, nem todas as atividades estão sujeitas ao licenciamento ambiental, apenas as que tenham potencial relevante para causar degradação ou poluição ambiental e as que utilizam em demasia os recursos naturais.

\section{O LICENCIAMENTO AMBIENTAL ONSHORE DO RN}

A Resolução CONAMA 023/94 foi expedida para estabelecer critérios para o licenciamento ambiental das atividades relacionadas à exploração e lavra de jazidas de combustíveis líquidos e gás natural, sendo que o controle e a expedição das licenças previstas competiriam ao órgão ambiental federal, Instituto Brasileiro de Meio Ambiente e Recursos Naturais Renováveis, IBAMA (MOLINA, 2005).

O licenciamento ambiental das atividades petrolíferas no mar (offshore), com base na localização do empreendimento e no alcance de seu impacto ambiental, cumpre ao IBAMA a competência de seu licenciamento de acordo com o art. $4^{\circ}$ da Resolução CONAMA 237/97.

Por outro lado, compete aos órgãos estaduais de meio ambiente, licenciar as atividades de exploração e produção de petróleo em terra (onshore). Sendo assim, por exemplo, o caso de estados como Amazonas, Bahia, Espírito Santo e Rio Grande do Norte, não utilizam os procedimentos e critérios constatados na Resolução CONAMA 023/94, mas sim a legislação ambiental estadual (MOLINA, 2005).

No caso do RN, o licenciamento ambiental é baseado na Política Estadual do Meio Ambiente (PEMA) estabelecida na Lei Complementar Estadual no 272 de 03 de março de 2004 e pela Lei Complementar Estadual n ${ }^{\circ} 336$ de 12 de dezembro de 2006. Em consonância com essas leis, o licenciamento ambiental onshore, face à sua complexidade em relação às outras atividades, é caracterizado por licenças mais específicas e numerosas do que o previsto na maioria dos empreendimentos. 
Em relação à atividade petrolífera onshore, para cada etapa exigem-se as seguintes licenças: a Licença Prévia para Perfuração (LPper), a Licença Prévia de Produção para Pesquisa (LPpro), a Licença de Instalação (LI) e, por fim, a Licença de Operação (LO), de acordo com a Lei Complementar $n^{\circ}$ 272/2004 (RIO GRANDE DO NORTE, 2004).

Em cada uma dessas licenças o órgão ambiental, no caso do nosso Estado o IDEMA, exige a apresentação de alguns documentos (ver Figura 2) que podem ser comuns em todas as licenças, mas também, há aqueles específicos como, por exemplo, os estudos ambientais.

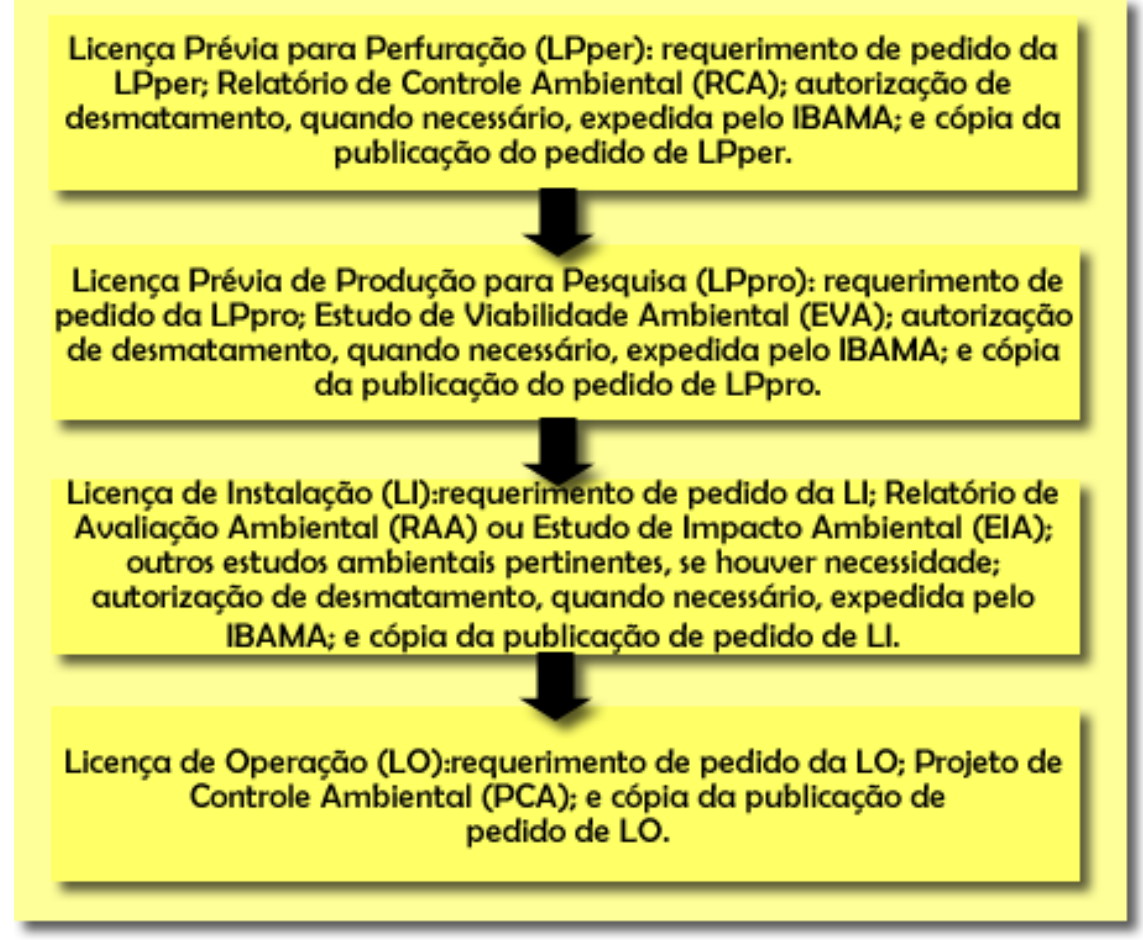

\section{Figura 2 - Documentos necessários para cada licença ambiental da atividade petrolífera onshore}

Fonte: Silva (2009), adaptado de Rio Grande do Norte (2004)

O RCA, um estudo ambiental objeto de nosso trabalho, é um desses documentos específicos que é solicitado no licenciamento da atividade petrolífera onshore para concessão da Licença Prévia para Perfuração (LPper).

\section{O ESTUDO AMBIENTAL}

O estudo ambiental, como afirma Sánchez (2006), é um estudo técnico com o intuito de fornecer as informações e análises técnicas de uma atividade causadora de impactos ambientais, desde a localização, implantação, operacionalização e ampliação, para subsidiar o processo de licenciamento.

Para a Resolução CONAMA no 237/97, o estudo ambiental é todo e quaisquer estudos relativos aos aspectos ambientais que estão relacionados à localização, instalação, operação e ampliação de uma atividade ou empreendimento. Como subsídio é apresentado para a análise da licença requerida, alguns estudos como: relatório ambiental, plano e projeto de controle ambiental, relatório ambiental preliminar, diagnóstico ambiental, plano de manejo, plano de recuperação de área degradada e análise preliminar de risco. 
Dentre os estudos ambientais inerentes ao licenciamento ambiental, o mais importante é o Estudo de Impacto Ambiental (EIA) e seu respectivo Relatório de Impacto Ambiental (RIMA). Esse estudo é um instrumento previsto na Constituição Federal é considerado o melhor modelo de prevenção de danos ao meio ambiente.

O RCA, objeto de nosso estudo nesse trabalho, foi criado para o caso de empreendimentos de pequeno potencial de impacto ambiental quando há a possibilidade de se estabelecerem procedimentos simplificados para o licenciamento ambiental (FINK et al 2004).

Nesse sentido, o RCA "foi criado para hipótese de dispensa do EIA/RIMA em casos de extração de minérios cujos empreendimentos sejam de menor porte” (FINK et al, 2004 p.8).

Esse estudo ambiental referente ao Licenciamento Prévio para Perfuração de Poços de Petróleo (LPper) do nosso Estado segue um roteiro (ver Figura 3), de acordo com o termo de referência do IDEMA (2006). O termo de referência, segundo Milaré (2005), é o ato por meio do qual o Poder Público formaliza a exigência de realização de um estudo ambiental como, por exemplo, um RCA. Ressaltamos que o item 7 desse roteiro, que é a respeito das "Medidas mitigadoras dos impactos ambientais", será o foco central do nosso trabalho.

\begin{tabular}{|c|}
\hline $\begin{array}{l}\text { 1. Identificação do empreendedor e do } \\
\text { empreendimento }\end{array}$ \\
\hline $\begin{array}{l}\text { 2. Identificação da empresa responsável pela } \\
\text { elaboração do RCA }\end{array}$ \\
\hline 3. Descrição técnica do empreendimento \\
\hline 4. Área de influência \\
\hline 5. Diagnóstico ambiental \\
\hline $\begin{array}{l}\text { 6. Identificação e análise dos impactos } \\
\text { ambientais }\end{array}$ \\
\hline $\begin{array}{l}\text { 7. Medidas mitigadoras dos impactos } \\
\text { ambientais }\end{array}$ \\
\hline $\begin{array}{l}\text { 8. Programa de acompanhamento e } \\
\text { monitoramento dos impactos ambientais }\end{array}$ \\
\hline 9. Conclusões \\
\hline 10. Equipe técnica \\
\hline 11. Bibliografia \\
\hline
\end{tabular}

Figura 3 - Roteiro de um RCA

Fonte: Silva (2009), adaptado do Termo de Referência para elaboração de um RCA referente ao Licenciamento Prévio de Perfuração de Poços Petrolíferos (2006).

\section{METODOLOGIA}

Para a consecução deste trabalho a metodologia deu-se inicialmente por meio de uma pesquisa exploratória realizada com levantamentos bibliográficos, documentais e legais, como a Lei 6.938/81 (PNMA), a resolução CONAMA 237/97, as Leis Complementares estaduais 272/03 e 336/06, além da contribuição de artigos científicos de anais e revistas, dissertações, livros, sites da internet, dentre outros. 
Dessa forma, podemos embasar os conceitos a cerca do principio do desenvolvimento sustentável no âmbito do Direito do Ambiente, do licenciamento ambiental tanto em âmbito geral quanto no licenciamento de atividades petrolíferas onshore, e por fim, o de estudo ambiental, destacando-se principalmente o Relatório de Controle Ambiental (RCA), que se constitui no objeto de análise deste trabalho científico.

O RCA escolhido é da empresa Petróleo Brasileiro S/A (PETROBRAS), elaborado pela Empresa de Consultoria e Planejamento Ambiental Ltda. (ECOPLAM), solicitado para emissão da Licença Prévia para Perfuração (LPper) de seis poços de petróleo no campo petrolífero de Porto Carão localizado na zona rural do município de Carnaubais (RN).

Para a análise em pauta, inicialmente, organizamos no Quadro 2, a fim de um melhor entendimento dos dados, todos os componentes ambientais considerados afetados pela atividade geradora de impacto, os impactos ambientais identificados e analisados para cada componente ambiental e, por fim, as medidas mitigadoras propostas para os respectivos impactos ambientais.

Depois, com o intuito de analisar as deficiências das medidas mitigadoras do RCA, realizamos uma comparação dessas medidas, que estão no item 7 (sete) do RCA, com as principais deficiências no item de "Mitigação e compensação de impactos" em estudos de impacto ambiental no Brasil, trabalho realizado pelo MPF (2004) no Quadro 1.

\section{Quadro 1 - Principais deficiências no item de mitigação e compensação de impactos em estudos de impacto ambiental no Brasil}

\begin{tabular}{|c|c|}
\hline $\begin{array}{l}\text { Elementos } \\
\text { do EIA }\end{array}$ & Principais deficiências \\
\hline \multirow{7}{*}{$\begin{array}{l}\text { Mitigação e } \\
\text { compensação } \\
\text { de impactos }\end{array}$} & Proposição de medidas que não é a solução para a mitigação do impacto. \\
\hline & Indicação de medidas mitigadoras pouco detalhadas. \\
\hline & $\begin{array}{c}\text { Indicação de obrigações ou impedimentos, técnicos e legais, como propostas de } \\
\text { medidas mitigadoras. }\end{array}$ \\
\hline & Ausência de avaliação da eficiência das medidas mitigadoras propostas. \\
\hline & $\begin{array}{l}\text { Deslocamento compulsório de populações: propostas iniciais de compensações } \\
\text { de perdas baseadas em diagnósticos inadequados. }\end{array}$ \\
\hline & $\begin{array}{c}\text { Não-incorporação de propostas dos grupos sociais afetados, na fase de } \\
\text { formulação do EIA. }\end{array}$ \\
\hline & $\begin{array}{l}\text { Proposição de Unidade de Conservação da categoria de uso sustentável para } \\
\text { aplicação dos recursos, em casos não previstos pela legislação. }\end{array}$ \\
\hline
\end{tabular}

Fonte: adaptado de MPF (2004) apud. Sánchez (2006)

Após essa análise comparativa, elaboramos o Quadro 3 demonstrando os aspectos ambientais, os componentes ambientais, os impactos ambientais, e, por fim, as medidas mitigadoras que apresentaram deficiências com base nessa comparação.

Por fim, discutimos esses resultados evidenciando as deficiências das medidas mitigadoras que compromete o princípio do desenvolvimento sustentável.

\section{RESULTADOS E DISCUSSÃO}

Neste capítulo apresentaremos as análises de deficiências das medidas mitigadoras do RCA para a perfuração de seis poços de petróleo no campo petrolífero de Porto Carão (município 
de Carnaubais, RN) com o objetivo de sabermos em que grau as medidas mitigadoras de impactos ambientais propostas por esse estudo ambiental, vêm apresentando deficiências que comprometem em sua qualidade e, conseguintemente, o princípio do desenvolvimento sustentável.

\section{INICIANDO A ANÁLISE DO ITEM 7 (SETE), MEDIDAS MITIGADORAS DOS IMPACTOS AMBIENTAIS, DO RCA}

Ao iniciarmos nossa análise do item 7 do RCA (ver Anexo 1), "Medidas mitigadoras dos impactos ambientais", identificamos que essas medidas foram apresentadas na matriz de impacto, em uma tabela, do item 6 (seis), que é um capítulo a respeito da "Identificação e análise dos impactos ambientais" do RCA em tela.

A nosso ver, a apresentação dessas medidas nessa matriz de impacto do item 6 (seis), não está em desconformidade com o termo de referência e não compromete a qualidade do RCA, pelo contrário, nesse caso, esclarece a relação entre impactos ambientais e suas respectivas medidas mitigadoras.

Contudo, ressaltamos que o item 7 (sete) do RCA (ver Anexo 1), que é referente às "Medidas mitigadoras dos impactos ambientais" apresentou deficiências quanto à apresentação de propostas de medidas mitigadoras pois, apesar de no texto mencioná-las no item 6 (seis), as recomendações apresentadas após isso (ver Anexo 1) não podem ser classificadas como medidas mitigadoras.

Essas medidas não possuem características como tais pelo fato de não existir uma relação direta com um impacto ambiental e, principalmente, por não possuir ações que têm como intuito reduzir a magnitude ou importância dos impactos ambientais negativos (SÁNCHEZ, 2006). Por isso, em nosso estudo, não levamos em consideração, ou melhor, não analisamos essas recomendações comentadas acima.

\section{IDENTIFICAÇÃO DA QUANTIDADE DE MEDIDAS MITIGADORAS DO RCA}

Prosseguindo com a análise das medidas mitigadoras do RCA, identificamos um total de 28 (vinte e oito) propostas de medidas mitigadoras, 8 (oito) componentes ambientais (do meio físico, do meio biológico e do meio antrópico) afetados pela atividade e 23 (vinte e três) impactos ambientais identificados e analisados, sendo que apenas 2 (dois) são positivos. No Quadro 2, são apresentados todos os componentes ambientais considerados afetados pela atividade geradora de impacto, o número de impactos ambientais identificados e analisados nos componentes ambientais e, por fim, o número de medidas mitigadoras de impactos ambientais. 
Quadro 2 - Componentes ambientais considerados afetados pela atividade geradora de impacto, número de impactos ambientais identificados e analisados nos componentes ambientais e o número de medidas mitigadoras de impactos ambientais.

\begin{tabular}{c|c|c}
\hline $\begin{array}{c}\text { Componentes ambientais } \\
\text { considerados afetados pela } \\
\text { atividade geradora de } \\
\text { impacto }\end{array}$ & $\begin{array}{c}\mathbf{N}^{\mathbf{0}} \text {. de impactos ambientais } \\
\text { identificados e analisados } \\
\text { nos componentes } \\
\text { ambientais }\end{array}$ & $\begin{array}{c}\mathbf{N}^{\mathbf{o}} \text { de medidas } \\
\text { mitigadoras dos } \\
\text { impactos ambientais }\end{array}$ \\
\hline Ar & 6 & 9 \\
\hline Solo & 6 & 9 \\
\hline Vegetação & 2 & 4 \\
\hline Fauna & 4 & 3 \\
\hline Água subterrânea & 1 & 0 \\
\hline $\begin{array}{c}\text { Patrimônio arqueológico e } \\
\text { paleontológico }\end{array}$ & 0 & 2 \\
\hline Meio antrópico & 2 & 28 \\
\hline Uso e ocupação do solo & 2 & 0 \\
\hline TOTAL & 23 & \\
\hline
\end{tabular}

Fonte: Silva (2009), adaptado de PETROBRAS (2008) e adaptado de Prado Filho e Souza (2004)

A maioria dos impactos ambientais e das proposições de mitigação ou eliminação desses impactos são referentes a componentes do meio físico e biológico. Essas medidas são mais numerosas do que as que dizem respeito ao meio antrópico. Atentamos que o componente ambiental "Uso e ocupação do solo" inclui-se como componente do "Meio antrópico", de acordo com a metodologia adotada no RCA para análise dos componentes ambientais susceptíveis a impactos. Em relação ao componente ambiental "Patrimônio arqueológico e paleontológico" constatamos que não foram detectados sítios na área ou nas imediações do empreendimento.

\section{ANÁLISE DE DEFICIÊNCIAS DAS MEDIDAS MITIGADORAS DO RCA}

Para uma análise das deficiências de medidas mitigadoras propostas no RCA, comparamos essas medidas com as principais deficiências no item de "Mitigação e compensação de impactos" em estudos de impacto ambiental no Brasil (Quadro 1), que é referente ao estudo do MPF (2004).

Dessa forma, temos como resultado o Quadro 3 que apresenta, para uma melhor visualização e entendimento dos dados, os Aspectos ambientais, os Componentes ambientais, os Impactos ambientais e as Medidas mitigadoras dos impactos ambientais deficientes no RCA em pauta. 
SILVA (2011)

\begin{tabular}{|c|c|c|c|}
\hline \multicolumn{4}{|c|}{$\begin{array}{c}\text { Quadro 3 - os Aspectos ambientais, os Componentes ambientais, os Impactos } \\
\text { ambientais e as Medidas mitigadoras deficientes }\end{array}$} \\
\hline $\begin{array}{l}\text { Aspectos } \\
\text { ambientais }\end{array}$ & $\begin{array}{c}\text { Componentes } \\
\text { ambientais }\end{array}$ & Impactos ambientais & \begin{tabular}{|c|}
$\begin{array}{c}\text { Medidas mitigadoras dos } \\
\text { impactos ambientais } \\
\text { deficientes }\end{array}$ \\
\end{tabular} \\
\hline \multirow{2}{*}{$\begin{array}{l}\text { Adequação do } \\
\text { terreno da locação } \\
\text { e abertura de } \\
\text { acessos }\end{array}$} & Vegetação & $\begin{array}{l}\text { Remoção da cobertura } \\
\text { da vegetação nativa. }\end{array}$ & $\begin{array}{c}\begin{array}{c}\text { Não há medidas mitigadoras a } \\
\text { considerar* }\end{array} \\
\end{array}$ \\
\hline & Fauna & $\begin{array}{l}\text { Destruição de ninhos e } \\
\text { tocas. }\end{array}$ & $\begin{array}{c}\text { Adoção do plano de } \\
\text { emergência do Ativo } \\
\text { Mossoró. } \\
\end{array}$ \\
\hline \multirow[b]{2}{*}{$\begin{array}{l}\text { Uso de máquinas } \\
\text { de combustão } \\
\text { interna }\end{array}$} & \multirow[b]{2}{*}{$\mathrm{Ar}$} & \multirow[b]{2}{*}{ Produção de Ruído. } & $\begin{array}{l}\text { Execução dos procedimentos } \\
\text { de ação de emergência. }\end{array}$ \\
\hline & & & \begin{tabular}{|c|}
$\begin{array}{l}\text { Utilização de equipamentos de } \\
\text { segurança (protetor auricular e } \\
\text { máscara). }\end{array}$ \\
\end{tabular} \\
\hline Cimentação & $\mathrm{Ar}$ & $\begin{array}{l}\text { Dispersão de poeira de } \\
\text { cimento. }\end{array}$ & $\begin{array}{l}\text { Manter os equipamentos em } \\
\text { áreas contidas e } \\
\text { procedimentos de emergência. }\end{array}$ \\
\hline \multirow{2}{*}{$\begin{array}{l}\text { Uso de máquinas } \\
\text { de combustão } \\
\text { interna }\end{array}$} & $\mathrm{Ar}$ & $\begin{array}{l}\text { Produção de ruído e } \\
\text { emissão de gases }\end{array}$ & $\begin{array}{l}\text { Os trabalhadores utilizarão } \\
\text { equipamentos de proteção } \\
\text { individual (protetor auricular). }\end{array}$ \\
\hline & Solo & \begin{tabular}{|c}
$\begin{array}{c}\text { Alteração da qualidade } \\
\text { do solo por perda de } \\
\text { combustível }\end{array}$ \\
\end{tabular} & $\begin{array}{l}\text { Execução dos procedimentos } \\
\text { de ação de emergência. }\end{array}$ \\
\hline \multirow{5}{*}{ Derrame de óleo } & \multirow[t]{2}{*}{ Solo } & \multirow[t]{2}{*}{$\begin{array}{l}\text { Impregnação do solo } \\
\text { por derrame de óleo. }\end{array}$} & $\begin{array}{c}\text { Adoção do plano de } \\
\text { emergência do Ativo de } \\
\text { Mossoró. }\end{array}$ \\
\hline & & & $\begin{array}{c}\text { Programa de monitoramento } \\
\text { da PETROBRAS }\end{array}$ \\
\hline & Água subterrânea & $\begin{array}{l}\text { Contaminação da água } \\
\text { por derrame de óleo }\end{array}$ & $\begin{array}{c}\text { Adoção do plano de } \\
\text { emergência do ativo de } \\
\text { Mossoró. }\end{array}$ \\
\hline & Vegetação & $\begin{array}{l}\text { Mortalidade da } \\
\text { cobertura vegetal na } \\
\text { área do acidente. } \\
\end{array}$ & $\begin{array}{c}\text { Adoção do plano de } \\
\text { emergência do Ativo de } \\
\text { Mossoró } \\
\end{array}$ \\
\hline & Fauna & $\begin{array}{c}\text { Mortalidade dos } \\
\text { animais em função da } \\
\text { contaminação por } \\
\text { óleo. } \\
\end{array}$ & $\begin{array}{c}\text { Adoção do plano de } \\
\text { emergência do Ativo de } \\
\text { Mossoró }\end{array}$ \\
\hline Produção & $\begin{array}{l}\text { Uso e ocupação do } \\
\text { Solo }\end{array}$ & $\begin{array}{l}\text { Interferência na } \\
\text { atividade existente. }\end{array}$ & $\begin{array}{c}\text { Adoção do plano de } \\
\text { emergência do Ativo de } \\
\text { Mossoró } \\
\end{array}$ \\
\hline
\end{tabular}

Legenda:

\section{Fonte: elaborado pelo autor (2009), adaptado de PETROBRAS (2008)}

$\square$ Indicação de medidas mitigadoras pouco detalhadas; e Proposição de medidas que não é a solução para a mitigação do impacto;

Indicação de obrigações ou impedimentos, técnicos e legais, como propostas de medidas mitigadoras;

Ausência de medidas mitigadoras (*deficiência classsificada pelo autor).

Conforme informações do Gráfico 2, constatamos que as medidas mitigadoras dos impactos ambientais do RCA não deficientes representam cerca de $54 \%$, ou o equivalente a 15 (quinze), do total de 28 medidas. 
Por outro lado, constatamos ainda que, do universo de 28 medidas mitigadoras que foram propostas pelo RCA cerca de $46 \%$ delas (ver Gráfico 2), o equivalente a 13 (treze), possuem deficiências que, inclusive, foi a ausência de medidas mitigadoras para o impacto ambiental "Remoção da cobertura da vegetação nativa" (ver Quadro 3, linha 2). A nosso ver, a ausência de medidas mitigadoras para esse impacto ambiental se constitui numa deficiência, haja vista que não foram propostas ações com o objetivo de reduzir a magnitude ou importância desse impacto negativo (SÁNCHEZ, 2006) e, além disso, descumpri o termo de referência e, conseqüentemente, a legislação vigente, comprometendo na qualidade do RCA.

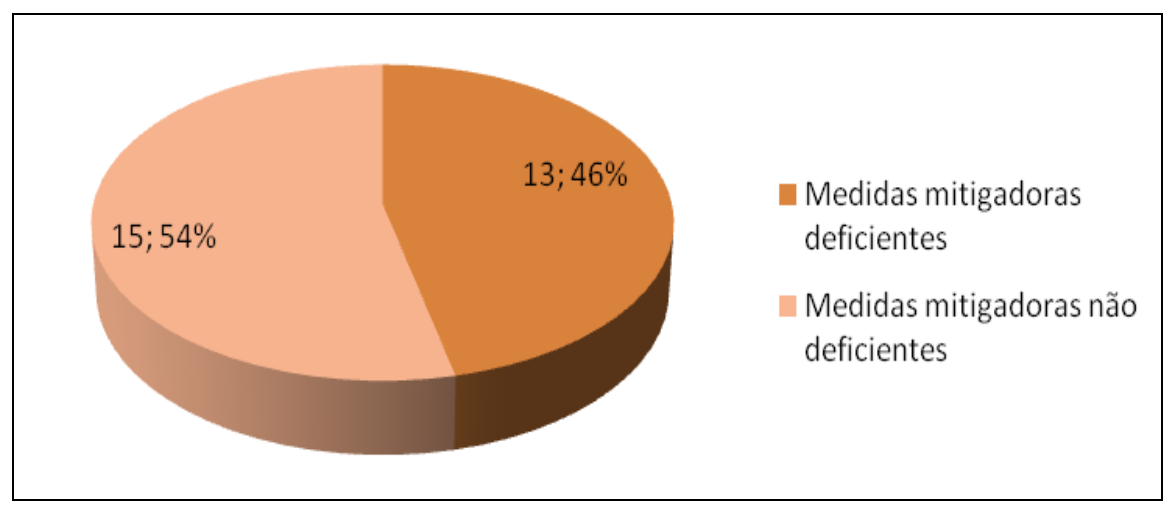

Gráfico 2 - Percentagem das medidas mitigadoras deficientes

Analisando as medidas deficientes do RCA, conforme comparação com as principais deficiências de medidas mitigadoras identificadas pelo MPF (2004), Quadro 1, constatamos que a maioria das medidas mitigadoras do RCA, $77 \%$ ou o equivalente a 10 (dez) de um total de 13 (treze) medidas deficientes, apresentaram cada uma delas dois tipos de deficiências: "Indicação de medidas mitigadoras pouco detalhadas" e "proposição de medidas que não são a solução para a mitigação do impacto", conforme Gráfico 3.

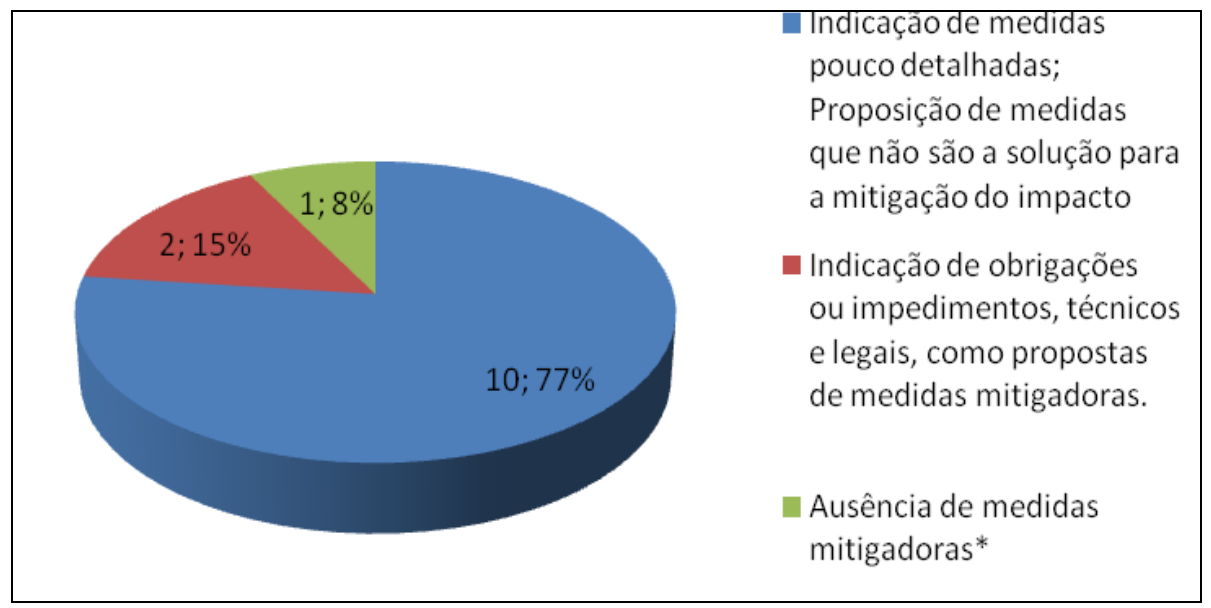

*Deficiência classsificada pelo autor

Gráfico 3 - As deficiências das medidas mitigadoras dos impactos ambientais do RCA

As medidas mitigadoras que se enquadraram nessas deficiências foram a "Adoção do plano de emergência do Ativo de Mossorô", o "Programa de monitoramento da PETROBRAS", "Execução dos procedimentos de ação de emergência" e "Manter os equipamentos em áreas contidas e procedimentos de emergência", pois, além do fato de serem ações pouco detalhadas, não apresentaram soluções para mitigar seus respectivos impactos ambientais.

Retomando as informações do Gráfico 3, notamos que $15 \%$ ou 2 (duas) medidas mitigadoras de um universo de 13 (treze) deficientes, são a cerca da deficiência "Indicação de obrigações ou impedimentos, técnicos e legais, como propostas de medidas mitigadoras". Nesse caso, 
constatamos que as medidas "Os trabalhadores utilizarão equipamentos de proteção individual (protetor auricular") e "Utilização de equipamentos de segurança (protetor auricular e máscara), são deficientes porque os equipamentos de segurança e proteção individual são exigências legais prevista na Lei 6.514 de 22 de dezembro de 1977. Ou seja, são medidas de cumprimento compulsório legal, como afirma Sánchez (2006), e, portanto não devem ser recomendadas como medidas mitigadoras, pois são simples obrigações legais que o empreendedor deve cumprir.

Ressaltamos que nessa análise comparativa não foram comparados com as medidas mitigadoras do RCA algumas deficiências do Quadro 1, pois não realizamos visitas ao empreendimento, justificando assim, a exclusão da análise da "Ausência de avaliação da eficiência das medidas mitigadoras propostas" do RCA em pauta.

Além disso, não analisamos os outros itens do RCA, senão o item 7 (sete), "Medidas mitigadoras dos impactos ambientais", justificando a exclusão da análise das seguintes deficiências do Quadro 1: "Deslocamento compulsório de populações: propostas iniciais de compensações de perdas baseadas em diagnósticos inadequados" e a "Não-incorporação de propostas dos grupos sociais afetados, na fase de formulação do EIA".

Finalmente, não analisamos se houve deficiência quanto a "Proposição de Unidade de Conservação da categoria de uso sustentável para aplicação dos recursos, em casos não previstos pela legislação", pois no RCA em tela não foram propostas medidas semelhantes à descrita acima.

\section{DISCUTINDO OS RESULTADOS SOB A ÓTICA DO PRINCÍPIO DO DESENVOLVIMENTO SUSTENTÁVEL}

Em suma, os resultados obtidos nesse trabalho constataram que $46 \%$ das medidas mitigadoras do RCA em estudo apresentaram deficiências como: a "Indicação de medidas mitigadoras pouco detalhadas", a "proposição de medidas que não são a solução para a mitigação do impacto", a "Indicação de obrigações ou impedimentos, técnicos e legais, como propostas de medidas mitigadoras" e a "Ausência de medidas mitigadoras".

Diante disso, essas medidas apresentaram deficiências que nos permite hesitar, como afirma Sánchez (2006), sobre suas funções primordiais na seguinte ordem de preferência: evitar impactos ou reduzir riscos, reduzir ou minimizar impactos negativos, compensar impactos negativos que não podem ser evitados e, finalmente, recuperar o ambiente degradado ao final de cada etapa do ciclo de vida do empreendimento.

Portanto, é inevitável questionarmos a garantia do direito e o dever ao meio ambiente ecologicamente equilibrado com condições favoráveis ao desenvolvimento de habilidades individuais e sociais das presentes e futuras gerações, haja vista, que para isso é necessário que a atividade atue de modo compatível com a preservação ambiental, com a responsabilidade social com os seus funcionários e com a sociedade: o que poderá não ocorrer diante dos resultados expostos.

Nesse sentido a nossa ótica, os resultados evidenciaram a ineficácia das medidas mitigadoras do RCA quanto suas funções comprometendo o princípio do desenvolvimento sustentável, esse que ocupa posição predominante no Direito Ambiental por influenciar, complementar e orientar os demais princípios. 


\section{CONSIDERAÇÕES FINAIS}

Com o intuito de analisarmos as deficiências das medidas mitigadoras de impactos ambientais propostas no RCA para perfuração de seis poços de petróleo no campo petrolífero de Porto Carão (Carnaubais, RN) e se essas atendem ao princípio do desenvolvimento sustentável, constatamos que $46 \%$, ou o equivalente a 13 (treze) medidas mitigadoras de um total de 28 (vinte oito), apresentam deficiências que podem implicar na qualidade desse estudo ambiental e, por conseguinte, não atendam ao princípio do desenvolvimento sustentável.

De acordo com os resultados alcançados nesse trabalho, o grau de deficiências encontradas nas medidas mitigadoras de impactos ambientais propostas pelo RCA é alto. Ainda que, consideramos que a análise em pauta não foi rígida, visto que não analisamos outras possíveis deficiências das medidas mitigadoras do RCA, quase metade dessas medidas possuía deficiências.

Nesse contexto, não é consentido que a empresa que desenvolverá a atividade, a empresa que elabora o estudo ambiental, e o órgão ambiental que o examina, atuem de modo aleatório e indiferente em relação à qualidade desse estudo, precisamente sobre as propostas de medidas mitigadoras de impactos ambientais deficientes, foco central desse trabalho.

Se assim persistirem, as medidas de controle ambiental que iriam promover a prevenção, diminuição e/ou compensação de impactos ambientais negativos da atividade petrolífera onshore não promoverá, como o esperado, o princípio do desenvolvimento sustentável, referência basilar no direito ambiental que deve ser, da melhor maneira possível, contemplado nas decisões tanto dessas empresas quanto do órgão ambiental para nortear a operacionalização do licenciamento ambiental como procedimento administrativo e instrumento de gestão do ambiente.

Além disso, ressaltamos que a qualidade de um estudo ambiental dependerá, primordialmente, de um bom termo de referência, roteiro básico para a elaboração dos estudos ambientais. Portanto, um bom termo de referência refletirá na qualidade de bons estudos ambientais.

Por fim, salientamos que o trabalho em pauta não pretende esgotar o tema estudado, pois, a propósito, pensamos que não temos condições de esgotá-lo. Além disso, pelo fato de ser um estudo de caso, os resultados desse trabalho não se emprega para os demais estudos ambientais da atividade petrolífera onshore do RN. Contudo, esses resultados são pertinentes, principalmente, pelo fato da atividade petrolífera onshore ocupar posição importante na economia do Estado e, por conseguinte, pela grande demanda de estudos ambientais referentes a essa atividade no IDEMA.

\section{REFERÊNCIAS}

1. BRASIL. Conselho Nacional do Meio Ambiente. Resolução n. ${ }^{\circ}$ 237, de 19 de dezembro de 1997. Regulamenta os aspectos do licenciamento ambiental estabelecidos na Política Nacional do Meio Ambiente. Disponível em: http://www.mma.gov.br/port/conama/res/res97/res23797.html. Acesso em: 15 jun. 2008

2. BRASIL. Conselho Nacional do Meio Ambiente. Resolução no. 023, de 07 de dezembro de 1994. Institui procedimentos específicos para o licenciamento das atividades relacionadas à exploração e lava de jazidas de combustíveis líquidos e gás natural. Disponível em: <http://www.lei.adv.br/023-94.htm>. Acesso em 02 de out. de 2008. 
3. BRASIL. Constituição (1988). Constituição da República Federativa do Brasil. Brasília, DF: Senado, 1988.

4. BRASIL. Lei n. 6.938, de 31 de agosto de 1981. Política Nacional do Meio Ambiente. Disponível em <http:// www.planalto.gov.br/ccivil_03/Leis/L6938.htm>. Acesso em: 30 jun. 2008.

5. FINK, Roberto Daniel; ALONSO JR, Hamilton; DAWALIBI, Marcelo. Aspectos jurídicos do licenciamento ambiental. Rio de Janeiro: Forense Universitária, 2004.

6. FOGLIATTI, Maria Cristina; FILIPPO, Sandro; GOUDARD, Beatriz; Avaliação de Impactos Ambientais: aplicação aos sistemas de transporte. Rio de Janeiro: Interciência, 2004.

7. MILARÉ, Edis. Direito do Ambiente: doutrina, jurisprudência, glossário. São Paulo: Revista dos Tribunais, 2. Ed. 2000.

8. _.Direito do Ambiente: doutrina, jurisprudência, glossário. 4. Ed.São Paulo: Revista dos Tribunais, 2005.

9. MOLINA, Adriana de Oliveira Varella, Licenciamento ambiental e Compensação Ambiental: aplicação na indústria de petróleo no Brasil. 2005. 252 f.Dissertação (Mestrado em Sistemas de Gestão) - Laboratório de Tecnologia, Gestão de Negócios e Meio Ambiente, Universidade Federal Fluminense, Rio de Janeiro, 2005. Disponível em: <http://biblioteca.universia.net/html_bura/ficha/params/id/29474457.html> Acesso em: 01 out. 2008.

10. RIO GRANDE DO NORTE (Estado). Política estadual de meio ambiente do estado do rio grande do norte. Lei complementar $n^{\circ}$ 272, de 03 de março de 2004. Disponível em: <http://www.rn.gov.br/secretarias/idema/legislacao.asp>. Acesso em: 25 set. 2008.

11. RIO GRANDE DO NORTE (Estado). Política estadual de meio ambiente do estado do rio grande do norte. Lei complementar $n^{0}$ 336, de 12 de dezembro de 2006: Altera a Lei Complementar Estadual $n^{\circ}$ 272, de 03de março de 2004 e dá outras providências. Disponível em: 〈http://www.gabinetecivil.rn.gov.br/acess/pdf/leicomp336.pdf〉. Acesso em: 25 set. 2008.

12. PETRÓLEO BRASILEIRO S.A. Relatório de Controle Ambiental (RCA). Perfuração de seis poços de petróleo no campo de Porto Carão, município de Carnaubais (RN). Natal, 2008.

13. SÁNCHEZ, Luis Enrique. Avaliação de impacto ambiental: conceitos e métodos. São Paulo: oficina de textos, 2006.

14. SILVA, Robson Garcia da. Análise das medidas mitigadoras de um relatório de controle ambiental sob a ótica do princípio do desenvolvimento sustentável. Natal, 2009. Monografia. IFRN, 2009.

15. PEGADO, Erika Araújo da Cunha; SILVA, Valdenildo Pedro da. Produção e difusão de conhecimentos tecnológicos sobre licenciamento ambiental onshore: uma experiência do Cefet-RN e do Prominp.In RIO OIL \& GAS EXPO AND CONFERENCE, 2008, Rio de Janeiro. Anais... Rio de Janeiro: Rio oil \& gas expo and conference, 2008. 1 CD ROM

16. PRADO FILHO, José Francisco do; SOUZA, Marcelo Pereira de. O licenciamento ambiental da mineração no quadrilátero ferrífero de Minas Gerais: uma análise da implementação de medidas de controle ambiental formuladas em EIAs/RIMAs. Revista Engenharia Sanitária e Ambiental, Rio de Janeiro, v.9, no 4, p.343-349, out/dez 2004. 
17. VIANNA, José Ricardo Alvarez. O Direito Ambiental e o princípio do desenvolvimento sustentável. Jus Navigandi, Teresina, ano 6, n. 57, jul.2002. Disponível em: http://jus2.uol.com.br/doutrina/texto.asp?id=2974 Acesso em: 23 abr. 2009. 


\section{Anexo 1 - Medidas Mitigadoras dos Impactos Ambientais do Relatório de Controle Ambiental (RCA) para Perfuração de seis de petróleo no campo de Porto Carão, município de Carnaubais (RN).}

\begin{tabular}{l|c|c|c}
\hline Ibli PETROBRAS & $\begin{array}{c}\text { Perfuração de Seis Poços de Petróleo no } \\
\text { Campo de Porto Carä́, Municipio de Carnaubais-RN. } \\
\text { Relatório de Controle Ambiental - RCA }\end{array}$ & $\begin{array}{c}7 \text { - Medidas } \\
\text { Impactigadoras dos }\end{array}$ & $\begin{array}{c}\text { Pag } \\
7-1 / 2\end{array}$ \\
\hline
\end{tabular}

\section{7 - MEDIDAS MITIGADORAS DOS IMPACTOS AMBIENTAIS}

As medidas mitigadoras e/ou compensatórias sugeridas para a minimização dos impactos ambientais que foram classificados como adversos ao meio físico, biológico e antrópico, especialmente desenvolvidas para reduzir os impactos potenciais previstos durante a execução do projeto dos poços PC 775-9421-751a, PC 777-9421-751, PC 777-9421-751a, PC 777-9421-751b, PC 777-9421-751c e PC 787-9421-751, são apresentadas ra matriz de impacto tabela 6.1-3 capitulo 6 (seis).

Recomendam-se, ainda, as seguintes medidas mitigadoras:

eseguir os procedimentos operacionais inerentes às atividades de perfuração dos poços.

\&Planejar as atividades de perfuração dos poços após o período de chuvas, evitando os transtornos de maquinários pesados em áreas suscetíveis à inundação.

Aanter os maquinários em adequado estado de funcionamento e de manutenção, para que operem perfeitamente, diminuindo ruidos e riscos de acidentes, como derrames de óleo (diesel ou lubrificantes) e graxas, durante a execução dos serviços. Se, eventualmente, ocorrer qualquer derrame com resíduo de óleos ou graxas, os mesmos deverão ser rapidamente recolhidos e encaminhados para descarte adequado, sendo recomendado o envio para a Central de Resíduos - Classe I, localizada no Campo de Estreito.

COs resíduos sólidos orgânicos gerados no campo e o material remanescente das atividades deverão ser coletados, ensacados separadamente para destinação adequada (aterro controlado).

\&Quanto aos resíduos gerados nas bases de perfuração, assim como no melhoramento do acesso, recomenda-se acondicionamento em recipientes apropriados para resíduos orgânicos e inorgânicos, como plásticos, latas, papéis, papelão, vidros, graxas e óleos. Quanto aos resíduos oleosos: graxas, óleos, panos, buchas, algodão ou similares utilizados para manutenção e limpeza dos equipamentos, recomenda-se o encaminhamento para a Central de Resíduos de Estreito.

«A conscientização dos operários em relação à fauna, para que não ocorra a caça, a comercialização, o aprisionamento, a destruição de ninhos e tocas, coleta de ovos, e maus tratos a animais silvestres, pelos membros

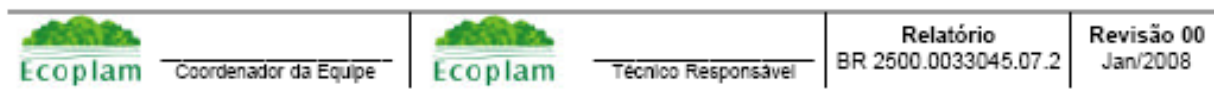

